\title{
HIF-1 $\alpha$ mediates the protective effect of plasma extracellular particles induced by remote ischaemic preconditioning on oxidative stress injury in human umbilical vein endothelial cells
}

\author{
MINGHUA WEN*, FENG HU* ${ }^{*}$ ZHIJIAN GONG, CHAHUA HUANG and XIAOSHU CHENG \\ Department of Cardiovascular Medicine, The Second Affiliated Hospital of Nanchang University, \\ Nanchang, Jiangxi 330006, P.R. China
}

Received July 17, 2020; Accepted October 15, 2021

DOI: $10.3892 /$ etm.2021.10970

\begin{abstract}
Remote ischaemic preconditioning (RIPC) is considered to alleviate myocardial ischaemia/reperfusion (I/R) injury. The present study explored whether blood plasma particulate matter, which is termed extracellular particles (EPs), and is released from cells during RIPC, could reduce $\mathrm{H}_{2} \mathrm{O}_{2}$-induced damage in human umbilical vein endothelial cells (HUVECs). Firstly, EPs were derived from volunteers who did or did not undergo RIPC. To induce RIPC in volunteers, a blood pressure cuff was alternatively inflated for $5 \mathrm{~min}$ and deflated for the same duration for four successive cycles. HUVECs were assigned to two groups: i) Group 1 was preincubated for $24 \mathrm{~h}$ with EPs from volunteers after sham-RIPC, then treated with $\mathrm{H}_{2} \mathrm{O}_{2}(1 \mathrm{mM} ; 6 \mathrm{~h})$ to mimic the in vivo conditions of I/R-induced oxidative stress; and ii) group 2 was preincubated for $24 \mathrm{~h}$ with EPs from volunteers after RIPC, then treated with $\mathrm{H}_{2} \mathrm{O}_{2}$. Subsequently, EPs were derived from rats received sham-RIPC or RIPC and/or cadmium (Cd) pre-treatment. To induce RIPC in rats, a remote hind limb preconditioning stimulus was delivered using a blood pressure cuff attached at the inguinal level of the rat. The blood pressure cuff was alternatively inflated for $5 \mathrm{~min}$ and deflated for the same time period for four successive cycles. HUVECs were assigned to six groups: i) Group 1 was untreated; ii) group 2 received only $\mathrm{H}_{2} \mathrm{O}_{2}$ treatment ( $1 \mathrm{mM} ; 6 \mathrm{~h}$ ); iii) group 3 was preincubated for $24 \mathrm{~h}$ with EPs from rats exposed to sham-RIPC, then treated with $\mathrm{H}_{2} \mathrm{O}_{2}$; iv) group 4 was preincubated for $24 \mathrm{~h}$ with EPs from rats that received an intraperitoneal injection of $1 \mathrm{mg} / \mathrm{kg} \mathrm{Cd}$
\end{abstract}

Correspondence to: Professor Xiaoshu Cheng, Department of Cardiovascular Medicine, The Second Affiliated Hospital of Nanchang University, 1 Minde Road, Nanchang, Jiangxi 330006, P.R. China

E-mail: xiaoshumenfan126@163.com

${ }^{*}$ Contributed equally

Key words: ischaemia/reperfusion injury, remote ischaemic preconditioning, extracellular particles, hypoxia-inducible factor 1- $\alpha$ [a pharmacological inhibitor of hypoxia-inducible factor 1- $\alpha$ (HIF-1 $\alpha$ ) in vivo] $180 \mathrm{~min}$ before sham-RIPC, then treated with $\mathrm{H}_{2} \mathrm{O}_{2}$; v) group 5 was preincubated for $24 \mathrm{~h}$ with EPs from rats exposed to RIPC, then treated with $\mathrm{H}_{2} \mathrm{O}_{2}$; and vi) group 6 was preincubated for $24 \mathrm{~h}$ with EPs from rats that received an intraperitoneal injection of $1 \mathrm{mg} / \mathrm{kg} \mathrm{Cd} 180 \mathrm{~min}$ before RIPC, then treated with $\mathrm{H}_{2} \mathrm{O}_{2}$. Cell viability and cytotoxicity were monitored using Cell Counting Kit-8 and lactate dehydrogenase assays. Cell apoptosis and necrosis were assessed via flow cytometry and western blot analysis. A notable increase in EP concentration in the plasma of volunteers after RIPC compared with that in the plasma of volunteers after sham-RIPC was observed. RIPC-associated EPs (RIPC-EPs) from volunteers could improve cell viability and reduce cytotoxicity, cell apoptosis and necrosis in HUVECs treated with $\mathrm{H}_{2} \mathrm{O}_{2}$ in vitro. Furthermore, RIPC caused a significant increase in HIF-1 $\alpha$ expression in the rat limb musculature. The apoptosis-reducing effect of RIPC-EPs was demonstrated to be counteracted by an intraperitoneal injection of $\mathrm{Cd}$ before RIPC in rats. A significant decrease in the EP levels precipitated from the plasma of rats that received $\mathrm{Cd}$ treatment before RIPC was observed compared with rats that did not receive $\mathrm{Cd}$ treatment. The present study suggested that HIF-1 $\alpha$ mediated at least partly the protective effect of plasma RIPC-EPs on oxidative stress injury in HUVECs.

\section{Introduction}

Remote ischaemic preconditioning (RIPC) is known to protect the heart against myocardial ischaemia/reperfusion (I/R) injury in numerous experimental and clinical settings (1-10), but the relevant mechanisms remain poorly understood. However, RIPC-associated cardio-protection may be mediated in part by the release of effector extracellular particles (EPs), including extracellular vesicles (EVs), lipoprotein particles and ribonucleoprotein particles, that activate cardioprotective pathways and lead to higher resistance of the heart to I/R injury (8-10). These particles carry non-coding RNAs, proteins and lipids that mediate cellular responses through autocrine, paracrine and endocrine mechanisms, and their composition and concentration vary under different pathophysiological conditions, such as hypoxia and radiation (10-13). At present, 
it is unclear whether the composition, concentration and function of plasma EPs change under RIPC conditions.

Hypoxia-inducible factor 1 (HIF-1) is a nuclear transcription factor composed of the HIF- $1 \alpha$ and HIF-1 $\beta$ subunits that regulates the transcription of hundreds of genes $(14,15)$. While HIF-1 $\beta$ is constitutively expressed, HIF- $1 \alpha$ is upregulated and stabilized in response to hypoxia. Therefore, HIF-1 activity is mainly dependent on the level of HIF-1 $\alpha$ expression $(14,15)$. Over the past decade, HIF-1 $\alpha$ has been established as a central regulator of oxygen homeostasis; it regulates energy utilization, oxidative stress, metabolism, cell survival and cell death through the transcriptional activation of hundreds of target genes (16). Hypoxia has been indicated to induce cardiomyocyte and pulmonary arterial smooth muscle cell proliferation in a HIF-1 $\alpha$-dependent manner (17). Emerging evidence in a previous study has also demonstrated that HIF-1 $\alpha$ mediated RIPC-associated protection against myocardial injury by activating interleukin-10 (IL-10) gene transcription (18).

The vascular endothelium, especially in the heart, could play a significant role in the RIPC-mediated mechanisms of heart protection from I/R injury $(19,20)$ : i) Humoral factors that are released into the circulatory systems under RIPC stimulus may directly interact with endothelial cells which directly or indirectly transfer the RIPC stimulus to the heart; ii) endothelial cells are among the first cell types that encounter hypoxia in the heart and respond to it; and iii) endothelial dysfunction is a central reason for severe local and systemic consequences of I/R injury. Moreover, endothelial changes and vascular dysfunction serve critical roles in $\mathrm{I} / \mathrm{R}$ injury $(19,20)$. These data indicated that the improvement of endothelial function may be one possible explanation for the protective effects of RIPC.

In the present study, healthy male volunteers were subjected to a RIPC protocol with a $12-\mathrm{cm}$-wide cuff placed around the upper nondominant arm $(21,22)$. A blood pressure cuff was alternatively inflated (up to $200 \mathrm{mmHg}$ ) for $5 \mathrm{~min}$ and deflated for the same duration for four successive cycles $(23,24)$ to induce RIPC. Laser Doppler blood flow (LDF) measurements were performed to confirm successful induction of transient upper limb ischaemia after RIPC treatment (25). EPs were derived from volunteers who did or did not undergo RIPC using an ultracentrifugation-based method (26). Human umbilical vein endothelial cells (HUVECs) were assigned to two groups: i) Group 1 was preincubated for $24 \mathrm{~h}$ with EPs from volunteers after sham-RIPC, then treated with $\mathrm{H}_{2} \mathrm{O}_{2}$ $(1 \mathrm{mM} ; 6 \mathrm{~h})$ mimicking the in vivo conditions of I/R-induced oxidative stress (27); and ii) group 2 was preincubated for $24 \mathrm{~h}$ with EPs from volunteers after RIPC, then treated with $\mathrm{H}_{2} \mathrm{O}_{2}$.

Moreover, a total of 32 8-week-old male Sprague Dawley rats were used in the present study. A remote hind limb preconditioning stimulus was delivered using a blood pressure cuff attached at the inguinal level of the rat. The blood pressure cuff was alternatively inflated (up to $150 \mathrm{mmHg}$ ) for $5 \mathrm{~min}$, then deflated for the same duration for four successive cycles to induce conditioning of the tissue $(23,24)$. EPs were derived from rats that received RIPC or sham-RIPC and/or cadmium (Cd) pre-treatment (28). HUVECs were assigned to six groups: i) Group 1 was untreated; ii) group 2 received only $\mathrm{H}_{2} \mathrm{O}_{2}$ treatment (1 mM; $6 \mathrm{~h}$ ); iii) group 3 was preincubated for $24 \mathrm{~h}$ with EPs from rats exposed to sham-RIPC, then treated with $\mathrm{H}_{2} \mathrm{O}_{2}$; iv) group 4 was preincubated for $24 \mathrm{~h}$ with EPs from rats that received an intraperitoneal injection of $1 \mathrm{mg} / \mathrm{kg}$ Cd (a pharmacological inhibitor of HIF-1 $\alpha$ in vivo) $180 \mathrm{~min}$ before sham-RIPC then treated with $\mathrm{H}_{2} \mathrm{O}_{2}$; v) group 5 was preincubated for $24 \mathrm{~h}$ with EPs from rats exposed to RIPC, then treated with $\mathrm{H}_{2} \mathrm{O}_{2}$; and vi) group 6 was preincubated for $24 \mathrm{~h}$ with EPs from rats that received an intraperitoneal injection of $1 \mathrm{mg} / \mathrm{kg} \mathrm{Cd} 180 \mathrm{~min}$ before RIPC, then treated with $\mathrm{H}_{2} \mathrm{O}_{2}$.

We hypothesized that EPs released during RIPC preconditioning in volunteers or rats could contribute to mitigating oxidative stress-induced damage, including cell viability, cytotoxicity, apoptosis and necrosis in HUVECs, and that these processes may further involve altered HIF-1 $\alpha$ expression.

\section{Materials and methods}

RIPC models. A total of 11 healthy male volunteers (mean age, 23.45 years; age range, $21-25$ years; mean body mass index, $24.42 \pm 1.38 \mathrm{~kg} / \mathrm{m}^{2}$ ) were recruited in the Second Affiliated Hospital of Nanchang University (Nanchang, China) between 18 and 20 July 2019 and examined in a temperature-controlled laboratory $\left(24-26^{\circ} \mathrm{C}\right)$. The exclusion criteria were as follows: i) Cardio-cerebro-vascular, pulmonary, liver, kidney, infectious or immune diseases; ii) alcohol or drug abuse; and iii) malignant tumours. The present study only included male volunteers to avoid potential effects of oestrogens (21). The volunteers were subjected to a RIPC protocol and treated with a 12-cm-wide cuff (OMRON Healthcare, Inc.) placed around the upper nondominant arm (22). Six volunteers were subjected to RIPC and five volunteers to sham-RIPC. To induce RIPC, the blood pressure cuff was alternatively inflated (up to $200 \mathrm{mmHg}$ ) for $5 \mathrm{~min}$ and deflated for the same duration for four successive cycles $(23,24)$. For volunteers subjected to sham-RIPC, the cuff was put around the arm without adding pressure. LDF measurements were performed to confirm successful induction of transient upper limb ischaemia after RIPC treatment.

The blood flow in the upper limb was diminished during RIPC compared to the sham-RIPC group, as measured using a laser Doppler flowmeter (Omegaflo FLO-C1 Omegawave Laser Tissue Blood Flow Meter; OMEGAWAVE, Inc.) (25). The probe for the blood flow (ML type; OMEGAWAVE, Inc.) and the thermistor for the temperature (TSD202F type; BIOPAC ${ }^{\circledR}$ Systems, Inc.) were attached to the ventral surface of the distal phalanx of the middle finger using surgical tape. The diameter and the penetration depth of the LDF probes were 15 and $1.0 \mathrm{~mm}$, respectively, and the diameter of the skin temperature sensor was $9.8 \mathrm{~mm}$. To reduce the risk of water intrusion between the probes and the skin and the influence of the medium temperature on the LDF measurement, the probes were covered by a custom-made heat insulator. The thermistor was connected to an amplifier (SKT100C type; BIOPAC ${ }^{\circledR}$ Systems, Inc.), and the finger skin blood flow and temperature were recorded at $200 \mathrm{~Hz}$ using a data acquisition and analysis software (MP150 software; v3.4.3; BIOPAC ${ }^{\circledR}$ Systems, Inc.) (25).

The volunteer characteristics and study design are presented in Fig. 1A and B. Written informed consent was obtained from all participants before they entered the present 
A

\begin{tabular}{lcccccccccccc}
\hline $\begin{array}{l}\text { Volunteer } \\
\text { identification }\end{array}$ & 1 & 2 & 3 & 4 & 5 & 6 & 7 & 8 & 9 & 10 & 11 & Mean \\
\hline Age (years) & 25 & 23 & 24 & 22 & 23 & 25 & 21 & 23 & 24 & 25 & 23 & 23.45 \\
Height (cm) & 170 & 173 & 169 & 173 & 175 & 172 & 176 & 168 & 172 & 173 & 170 & 171.91 \\
Weight (kg) & 71 & 73 & 65 & 80 & 81 & 67 & 75 & 69 & 72 & 68 & 73 & 72.18 \\
\hline
\end{tabular}

B

1 Sham-RIPC-EP

2 RIPC-EP

C

1 Sham-RIPC-EP $+\mathrm{H}_{2} \mathrm{O}_{2}$-treated

2 RIPC-EP $+\mathrm{H}_{2} \mathrm{O}_{2}$-treated
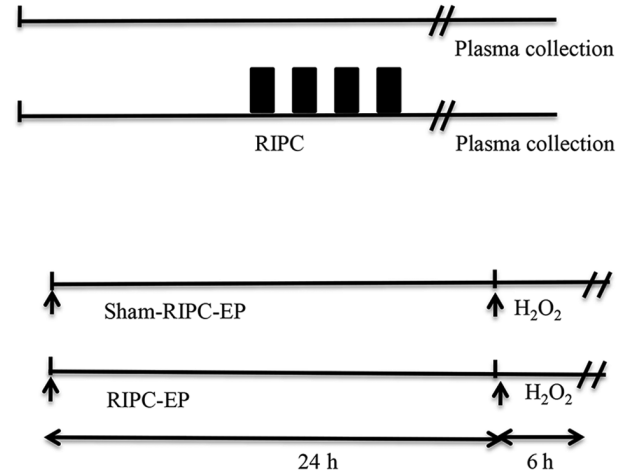

Figure 1. Study design of RIPC intervention on healthy male volunteers. (A) Data from 11 healthy male volunteers (mean age, 23.45 years; age range, 21-25 years; mean body mass index, $24.42 \pm 1.38 \mathrm{~kg} / \mathrm{m}^{2}$ ). (B) Study design of RIPC intervention on volunteers. (C) Study design to examine the effects of volunteer RIPC-induced EPs on human umbilical vein endothelial cells treated with $\mathrm{H}_{2} \mathrm{O}_{2}$. RIPC, remote ischaemic preconditioning; EP, extracellular particle.

study. The present study was conducted in accordance with The Declaration of Helsinki and was approved by the Ethics Committee of the Second Affiliated Hospital of Nanchang University [approval no. SYXK(G) 2019-0007; Nanchang, China].

A total of 32 8-week-old male Sprague Dawley rats (weight, 150-200 g) were used in the present study. The animals were supplied by the Animal Research Department of Nanchang University. Rats were kept under standard conditions at $22 \pm 2^{\circ} \mathrm{C}$, with indoor sterile fresh air and a 12-h light-dark cycle with free access to water and food. Humidity levels were between 45 and $55 \%$. The rats were anaesthetized with pentobarbital sodium (40 mg/kg; intraperitoneal injection). A remote hind limb preconditioning stimulus was delivered using a 1-cm-wide blood pressure cuff (OMRON Healthcare, Inc.) attached at the inguinal level of the rat. The blood pressure cuff was alternatively inflated (up to $150 \mathrm{mmHg}$ ) for $5 \mathrm{~min}$, then deflated for the same duration for four successive cycles to induce conditioning of the tissue (Fig. 2A) $(23,24)$. Using 3.5x magnifying surgical glasses, venous congestion was observed during occlusion, which was rapidly followed by brisk reactive hyperaemia during reperfusion. The body temperature was maintained at $37^{\circ} \mathrm{C}$. The reproducibility and reliability of the method of inducing rat lower-limb ischaemia has been verified via a modified pulse oximetry protocol for use in rats (24). A total of $180 \mathrm{~min}$ before RIPC stimulus, rats received a single intraperitoneal injection of $1 \mathrm{mg} / \mathrm{kg} \mathrm{Cd}$ chloride (MilliporeSigma) dissolved in PBS in RIPC-EP group (28).

After the study, the rats were anaesthetized by isoflurane inhalation (3\%) plus $1 \mathrm{l} / \mathrm{min} \mathrm{O}_{2}$ and euthanized by exsanguination. Rat limb muscle tissues and blood were isolated from rats after sacrifice and were stored at $-20^{\circ} \mathrm{C}$.
All animal experiments were conducted in compliance with the Guide for the Care and Use of Laboratory Animals published by the US National Institutes of Health (NIH publication no. 85-23, revised 1996) and were approved by the Ethics Committee of the Second Affiliated Hospital of Nanchang University [approval no. SYXK(G) 2019-0102; Nanchang, China].

Plasma collection, plasma preparation and extracellular particle enrichment. Human volunteer $(10 \mathrm{ml})$ and rat blood samples $(10 \mathrm{ml})$ were collected immediately after sham-RIPC or RIPC into $\mathrm{K}_{2}$ EDTA tubes (BD Biosciences) and processed within $5 \mathrm{~min}$ for plasma preparation. The blood samples were first centrifuged at 1,500 x $\mathrm{g}$ for $15 \mathrm{~min}$ at room temperature. The supernatants were collected and transferred to nuclease-free tubes. EPs were enriched using an ultracentrifugation-based method according to methods described previously (26). Briefly, $10 \mu \mathrm{l}$ of $500 \mathrm{U} / \mathrm{ml}$ thrombin were added to $1 \mathrm{ml}$ of plasma. The solution was incubated for $5 \mathrm{~min}$ at room temperature and centrifuged for $5 \mathrm{~min}$ at $2,000 \mathrm{x} \mathrm{g}$ at $4^{\circ} \mathrm{C}$. Subsequently, the plasma was filtered using a $0.22-\mu \mathrm{m}$ pore filter (Steradisc; Kurabo Industries Ltd. Bio-Medical Department). Next, the filtrate was ultracentrifuged at $100,000 \times \mathrm{g}$ for $70 \mathrm{~min}$ at $4^{\circ} \mathrm{C}\left(\right.$ Optima $^{\mathrm{TM}} \mathrm{XE}-90$ ultracentrifuge with a swing rotor; cat. no. SW41Ti; Beckman Coulter, Inc.). The cell-free plasma samples were mixed well with ExoQuick ${ }^{\mathrm{TM}}$ Exosome Precipitation Solution (cat. no. EXOQ5A-1; Shanghai Yeasen BioTechnologies Co., Ltd.). After the mixtures were incubated at $4^{\circ} \mathrm{C}$ for $30 \mathrm{~min}$ and centrifuged at $4^{\circ} \mathrm{C}$ at $1,500 \times \mathrm{g}$ for $30 \mathrm{~min}$, the obtained pellets were washed with PBS. Then, the EP pellets were dissolved in $20 \mu 1 \mathrm{PBS}$ and stored at $-80^{\circ} \mathrm{C}$ until further use. 
A

1 Sham-RIPC-EP

2 Cd-sham-RIPC-EP

3 RIPC-EP

4 Cd-RIPC-EP

B

1 Control

$2 \mathrm{H}_{2} \mathrm{O}_{2}$-treated

3 Sham-RIPC-EP+ $\mathrm{H}_{2} \mathrm{O}_{2}$-treated

4 Cd-sham-RIPC-EP $+\mathrm{H}_{2} \mathrm{O}_{2}$-treated

5 RIPC-EP $+\mathrm{H}_{2} \mathrm{O}_{2}$-treated

6 Cd-RIPC-EP $+\mathrm{H}_{2} \mathrm{O}_{2}$-treated
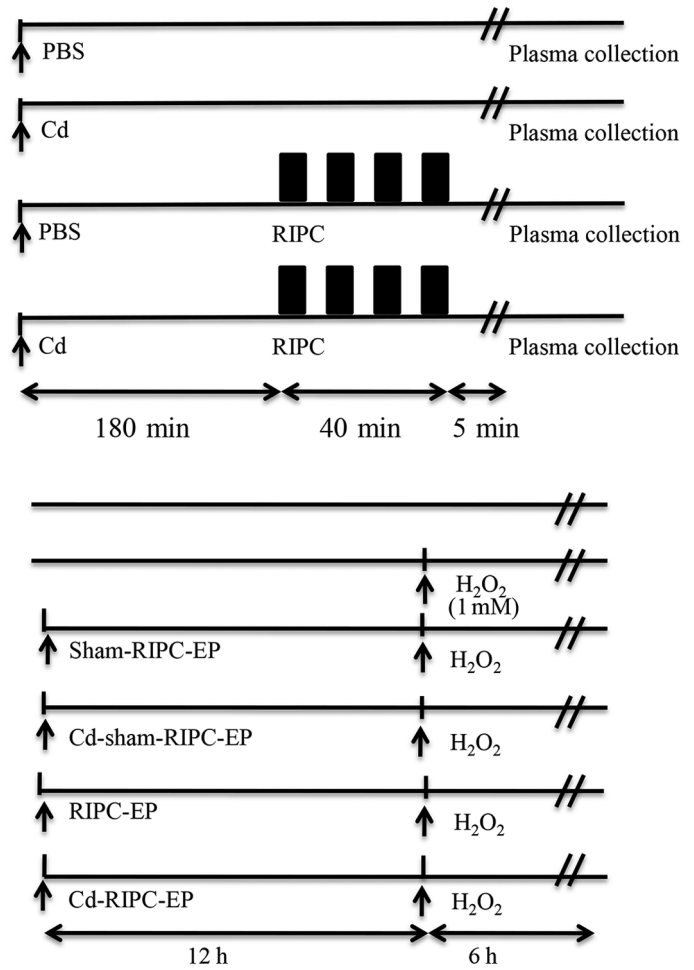

Figure 2. Study design of RIPC and Cd intervention in rats and human umbilical vein endothelial cells. (A) Study design of RIPC and Cd intervention in rats. (B) Study design to examine the role of hypoxia-inducible factor 1- $\alpha$ in mediating the protective effect of rat RIPC-associated EPs on human umbilical vein endothelial cells treated with $\mathrm{H}_{2} \mathrm{O}_{2}$. RIPC, remote ischaemic preconditioning; EP, extracellular particle; HIF-1 $\alpha$, hypoxia-inducible factor 1- $\alpha$; Cd, cadmium.

Extracellular particle characterization by transmission electron microscopy (TEM). TEM was used to observe exosome morphology (Hitachi H-7100 microscope; Hitachi High-Technologies Corporation). For exosome TEM observation, exosomes were fixed with $2.5 \%$ glutaraldehyde at $4^{\circ} \mathrm{C}$ overnight. After washing, the samples were prepared by dropping $4 \mu \mathrm{l}$ of exosome solution onto a formvar-coated copper grid (Sigma-Aldrich; Merck $\mathrm{KGaA}$ ) for 2 min at $25^{\circ} \mathrm{C}$, negatively stained with aqueous phosphotungstic acid for $60 \mathrm{sec}$ at $25^{\circ} \mathrm{C}$, and images were taken with a transmission electron microscope at $80 \mathrm{kV}$ (magnification, x500,000; Hitachi H-7100 microscope; Hitachi High-Technologies Corporation). The images were observed using Image-Pro Plus (v6.0; Media Cybernetics, Inc.).

Nanoparticle tracking analysis (NTA). Analysis of the EP size distribution was performed using NanoSight NS300 (Malvern Instruments, Ltd.). The particles were automatically tracked and sized based on their Brownian motion and the diffusion coefficient. Resuspended EPs were diluted in $1 \mathrm{ml}$ sterile PBS. Sterile PBS samples were used to assess background. The NTA measurement conditions were a temperature of $23.75 \pm 0.5^{\circ} \mathrm{C}, 25$ frames per sec and a measurement time of $60 \mathrm{sec}$. The detection threshold was identical in all samples. Three recordings were performed three times for each sample.

Cell culture and treatment. HUVECs were purchased from the American Type Culture Collection (https://www.atcc. org/products/pcs-100-010; cat. no. PCS-100-010) and cultured in DMEM (HyClone; Cytiva) supplemented with 10\% FBS
(Gibco; Thermo Fisher Scientific, Inc.), $100 \mathrm{U} / \mathrm{ml}$ penicillin and $100 \mathrm{mg} / \mathrm{ml}$ streptomycin in a humidified atmosphere containing $5 \% \mathrm{CO}_{2}$ at $37^{\circ} \mathrm{C}$. HUVECs were treated with $\mathrm{H}_{2} \mathrm{O}_{2}$ (MilliporeSigma) at different concentrations $(0.1,1$ and $10 \mathrm{mM})$ for $6 \mathrm{~h}$ to induce cell apoptosis and necrosis, thus mimicking the in vivo conditions of I/R-induced oxidative stress (27).

Confirmation of EP transfer into HUVECs with PKH26 dye. EPs precipitated from volunteer plasma after RIPC were mixed with PKH26 Red Fluorescent Cell Linker kit for General Cell Membrane Labeling (MilliporeSigma) for 4 min at $4^{\circ} \mathrm{C}$, following the manufacturer's instructions. Subsequently, the reaction was terminated by incubation with FBS for 5 min at $4^{\circ} \mathrm{C}$. The labelled material was washed three times with PBS to remove the excess dye and incubated with HUVECs grown to $70-80 \%$ density seeded on six-well plates for $10 \mathrm{~min}$ at $25^{\circ} \mathrm{C}$. The cell nuclei were stained with DAPI (cat. no. C0065; Beijing Solarbio Science \& Technology Co., Ltd.) for $10 \mathrm{~min}$ at $25^{\circ} \mathrm{C}$, and all stained sections were viewed by confocal microscope (magnification, x500, Olympus Corporation). The data were visualized and quantified using Image-Pro Plus v6.0 (Media Cybernetics, Inc.).

Study groups and experimental protocol. The present study was divided into two parts. In the first part, EPs were derived from volunteers treated or non-treated with RIPC. HUVECs were assigned to two groups: i) Group 1 included HUVECs that were preincubated for $24 \mathrm{~h}$ with $4 \mu \mathrm{l}$ EPs $\left(1 \times 10^{9}\right.$ nanoparticles/ml) from volunteers after sham-RIPC, then treated with $\mathrm{H}_{2} \mathrm{O}_{2}(1 \mathrm{mM} ; 6 \mathrm{~h})$; ii) group 2 included HUVECs that were 
preincubated for $24 \mathrm{~h}$ with $4 \mu \mathrm{l}$ EPs $\left(1 \times 10^{9}\right.$ nanoparticles $\left./ \mathrm{ml}\right)$ from volunteers after RIPC, then treated with $\mathrm{H}_{2} \mathrm{O}_{2}(1 \mathrm{mM} ; 6 \mathrm{~h})$. The study design is presented in Fig. 1C. In the second part, EPs were derived from rats that did or did not receive RIPC and $\mathrm{Cd}$ treatment. HUVECs were assigned to six groups: i) Group 1 (control) were untreated cells; ii) group 2 received only $\mathrm{H}_{2} \mathrm{O}_{2}$ treatment ( $1 \mathrm{mM}$; $6 \mathrm{~h})$; iii) group 3 was preincubated for $24 \mathrm{~h}$ with $4 \mu \mathrm{l}$ EPs $\left(1 \times 10^{9}\right.$ nanoparticles $\left./ \mathrm{ml}\right)$ from rats exposed to sham-RIPC, then treated with $\mathrm{H}_{2} \mathrm{O}_{2}(1 \mathrm{mM} ; 6 \mathrm{~h})$; iv) group 4 was preincubated for $24 \mathrm{~h}$ with $4 \mu \mathrm{l}$ EPs $\left(1 \times 10^{9}\right.$ nanoparticles $\left./ \mathrm{ml}\right)$ from rats exposed to sham-RIPC that received an intraperitoneal injection of $1 \mathrm{mg} / \mathrm{kg} \mathrm{Cd}$ [MilliporeSigma; the dose was based on the minimal dose required to enhance HIF-1 $\alpha$ degradation $(29,30)$ by the proteasome (31) via an effect on the ubiquitin system (32)] 180 min before sham-RIPC, then treated with $\mathrm{H}_{2} \mathrm{O}_{2}$ $(1 \mathrm{mM} ; 6 \mathrm{~h}) ; \mathrm{v})$ group 5 was preincubated for $24 \mathrm{~h}$ with $4 \mu \mathrm{l} \mathrm{EPs}$ $\left(1 \times 10^{9}\right.$ nanoparticles $\left./ \mathrm{ml}\right)$ from rats exposed to RIPC, then treated with $\mathrm{H}_{2} \mathrm{O}_{2}(1 \mathrm{mM} ; 6 \mathrm{~h})$; and vi) group 6 was preincubated for $24 \mathrm{~h}$ with $4 \mu \mathrm{l}$ EPs ( $1 \times 10^{9}$ nanoparticles $\left./ \mathrm{ml}\right)$ from rats exposed to RIPC that received an intraperitoneal injection of $1 \mathrm{mg} / \mathrm{kg} \mathrm{Cd}$ 180 min before RIPC, then treated with $\mathrm{H}_{2} \mathrm{O}_{2}(1 \mathrm{mM} ; 6 \mathrm{~h})$. The study design is presented in Fig. 2A and B.

In vitro lactate dehydrogenase $(\mathrm{LDH})$ and cell viability assays. HUVECs were exposed to $1 \mathrm{mM} \mathrm{H}_{2} \mathrm{O}_{2}$ for $6 \mathrm{~h}$ in the presence or absence of RIPC-EPs. LDH release, used as a marker of cell injury, was quantified using a CytoTox-ONE ${ }^{\mathrm{TM}}$ Homogeneous Membrane Integrity Assay (cat. no. G7890; Promega Corporation) according to the manufacturer's protocol. Cell viability was determined by a Cell Counting Kit-8 (CCK-8; cat. no. C0037; Beyotime Institute of Biotechnology) according to the manufacturer's protocol. HUVECs were incubated with $10 \mu \mathrm{mol}$ CCK- 8 solution at $37^{\circ} \mathrm{C}$ for $2 \mathrm{~h}$. The absorbance at $450 \mathrm{~nm}$ was measured using a microplate reader (Bio-Rad Laboratories, Inc.). Cell viability was calculated based on the relative optical density compared with that of untreated controls.

Flow cytometry detection of apoptosis and necrosis. After treatment with $\mathrm{H}_{2} \mathrm{O}_{2}$ or EPs, cell apoptosis and necrosis were assayed using the FITC Annexin V Apoptosis Detection kit (cat. no. KGA108; Nanjing KeyGen Biotech Co., Ltd.) following the manufacturer's instructions. Briefly, HUVECs were washed in PBS three times and resuspended in $400 \mu \mathrm{l}$ of binding buffer with FITC Annexin-V and propidium iodide (PI; $5 \mu l$ each). The cell suspension was incubated for $15 \mathrm{~min}$ at room temperature in the dark, then analyzed by flow cytometry (BD FACSCanto ${ }^{\mathrm{TM}} \mathrm{II}$; BD Biosciences) within $1 \mathrm{~h}$. The indexes of apoptosis and necrosis were calculated by the FlowJo software (v10.4.2; BD Biosciences). The apoptosis index was expressed as the percentage of total apoptotic cells, which included the percentage of early apoptotic cells (Annexin V-positive and PI-negative) plus the percentage of late apoptotic cells (Annexin V-positive and PI-positive). The index of necrosis was expressed as the percentage of necrotic cells (Annexin V-negative and PI-positive).

Western blot analysis. The characterization of the EP precipitates was performed via western blotting, and the proteins were isolated from cultured HUVECs or rat limb musculature tissue samples by lysis in RIPA buffer containing protease inhibitors (MilliporeSigma). The protein concentration was assessed using a BCA Protein Assay kit (MilliporeSigma). Equal amounts of protein $(30 \mu \mathrm{g})$ were separated via $10 \%$ SDS-PAGE and transferred to PVDF membranes (MilliporeSigma). The PVDF membranes were then blocked for $1 \mathrm{~h}$ at room temperature in 5\% non-fat dry milk and incubated overnight at $4^{\circ} \mathrm{C}$ with primary antibodies [anti- $\beta$-tubulin (1:1,000; Abcam; cat. no. ab210797), anti-CD31 (1:1,000; Abcam; cat. no. ab281583), anti-CD63 (1:1,000; Abcam; cat. no. ab59479), anti-CD9 (1:1,000; Abcam; cat. no. ab92726), anti-CD81 (1:1,000; Abcam; cat. no. ab79559), anti-HIF-1a (1:1,500; Abcam; cat. no. ab1), anti-caspase-3 (1:1,000; Cell Signaling Technology, Inc., cat. no. 9662) and anti-cleaved caspase-3 (1:1,000; Cell Signaling Technology, Inc., cat. no. 9661)]. After washing with TBST (0.1\% Tween 20), immunoreactive bands were incubated with HRP-conjugated Goat Anti-mouse IgG $(\mathrm{H}+\mathrm{L})$ secondary antibody $(1: 5,000$; BA1051; Wuhan Boster Biological Technology, Ltd.) or HRP-conjugated Goat Anti-rabbit $\operatorname{IgG}(\mathrm{H}+\mathrm{L})$ antibody $(1: 5,000$; cat. no. BA1055; Wuhan Boster Biological Technology, Ltd.) for $1 \mathrm{~h}$ at $25^{\circ} \mathrm{C}$. Immunoreactive bands were visualized using enhanced chemiluminescence reagents (ECL; Thermo Fisher Scientific, Inc.) with a ChemiDoc ${ }^{\mathrm{TM}} \mathrm{XRS}+$ luminescent image analyser (v4.0; Bio-Rad Laboratories, Inc.). The results were normalized to those of $\beta$-tubulin.

ELISA-based measurement of plasma HIF-1 $\alpha$ activation. Blood samples of rats were collected immediately at the end of the four cycles of 5-min exposures to RIPC or sham-RIPC treatment. Nuclear extracts were obtained with a commercial kit (Nuclear Extraction kit; cat. no. ab113474; Abcam), according to the manufacturer's instructions. Activation of HIF-1 $\alpha$ was quantified by a DNA-binding TransAM ${ }^{\circledR}$ HIF-1 Transcription Factor ELISA kit (cat. no. 47096; Active Motif, Inc.), according to the manufacturer's protocol and based on the binding of activated HIF-1 $\alpha$ to an oligonucleotide containing a hypoxia response element (5'-TACGTGCT-3') from the erythropoietin gene.

Statistical analysis. The data are presented as the mean \pm SEM. The D'Agostino and Pearson omnibus normality test was used for testing data normality. Statistical analysis was performed with GraphPad Prism 6.0 Software (GraphPad Software, Inc.). Unpaired Student's t-test was used for comparing data between two groups. One-way ANOVA was conducted followed by Tukey's post hoc test for comparisons between $>2$ groups. $\mathrm{P}<0.05$ was considered to indicate a statistically significant difference.

\section{Results}

Circulating EPs are more abundant in the plasma from RIPC-compared with sham-treated human subjects. LDF measurements were performed to confirm successful induction of transient upper limb ischaemia via RIPC treatment in volunteers, as measured using a laser Doppler flowmeter (Fig. 3A and B). The blood flow in the upper limb was diminished during RIPC and recovered after the blood pressure meter deflated. The EV markers CD63, CD9 and CD81 $(8,25)$ appeared to be expressed more abundantly in plasma from volunteers after RIPC compared with the sham-RIPC-EP 

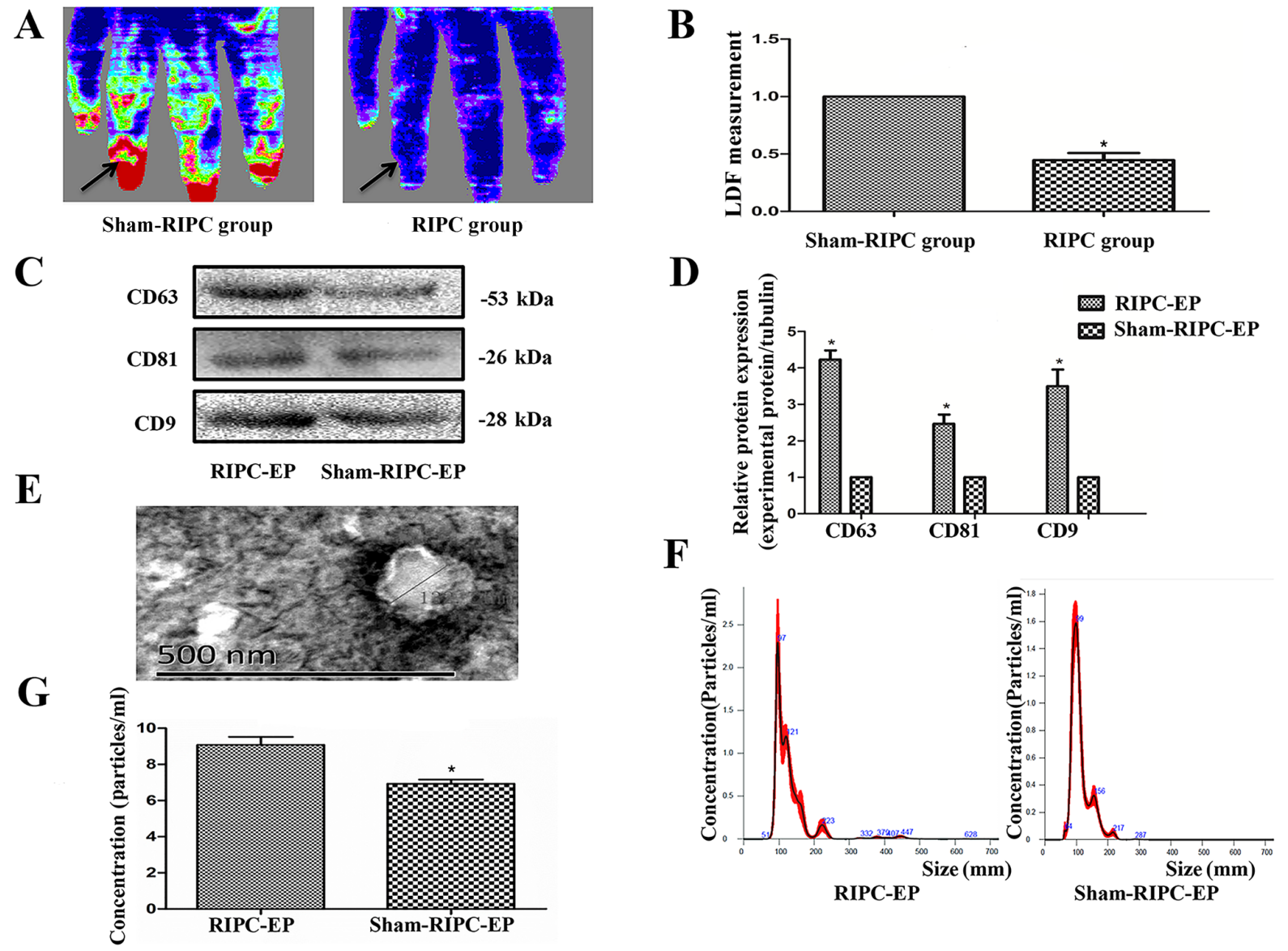

Figure 3. Establishment of the RIPC model and characterization of plasma EPs. (A) LDF measurements were performed to confirm successful induction of transient upper limb ischaemia after RIPC treatment. The blood flow in the upper limb was diminished during RIPC and recovered after the blood pressure meter deflated. This was measured using a laser Doppler flowmeter (Omegaflo FLO-C1 Omegawave Laser Tissue Blood Flow Meter; OMEGAWAVE, Inc.). (B) Computer-assisted quantitative analysis indicated a significant decrease in the flow rate after pressurization. ${ }^{*} \mathrm{P}<0.05$, the sham-RIPC group vs. the RIPC group, $n=4$. (C) Western blot analysis demonstrated that the protein expression levels of the EP markers CD63, CD9 and CD81 appeared to be higher in volunteer plasma after RIPC. (D) Western blotting quantification based on three blots. ${ }^{\mathrm{P}}<0.05$ vs. the sham-RIPC-EP group, $\mathrm{n}=3$. (E) Transmission electron microscopy of purified exosomes from volunteers, $\mathrm{n}=3$. Scale bar=500 nm. (F) Nanoparticle tracking analysis demonstrated the similar variance in exosome size within the range of 50-150 nm (average, $108 \mathrm{~nm}$ ) in RIPC-associated EPs and sham-RIPC-associated EPs derived from equal volumes of volunteer plasma, $\mathrm{n}=3$. (G) The concentration of the RIPC-associated EPs was higher compared with that of the sham-RIPC-associated EPs. "P<0.05 vs. the sham-RIPC-EP group, $\mathrm{n}=4$. RIPC, remote ischaemic preconditioning; EP, extracellular particle; LDF, laser Doppler blood flow.

group (Fig. 3C and D); this result was likely due to the pressure-induced activation of platelets (12). An approximately spherical structure was observed within the EV population using TEM, with a diameter of $\sim 130 \mathrm{~nm}$ (Fig. 3E). NTA, an optical method of detecting particles of $\sim 90 \mathrm{~nm}$ in diameter or larger, detected particles with a median size of just $>100 \mathrm{~nm}$ in both types of volunteer plasma (Fig. 3F). RIPC appeared to increase the total number of EPs in the volunteer plasma, again likely due to platelet activation (Fig. 3G). In the present experiments, no differences between the EPs from human or rat blood after ischaemia were noticed in EV markers (CD63, CD9 and CD81), with similar roughly spherical structure and size distribution (data not shown).

Exosome labelling and uptake by HUVECs. Western blot analysis confirmed HUVEC expression of CD31, a marker of endothelial cells (33) (Fig. 4A). To determine whether HUVECs could take up particles labelled by a fluorescent dye, EPs from volunteers were firstly labelled with PKH26, a fluorescent dye that stains EVs and other EPs. After labelling, fluorescence was detected in the EP fraction. When the HUVECs were incubated with the PKH26-labelled EPs, fluorescence could be observed in the cytoplasm (Fig. 4B), which indicated that the dye had been taken up by HUVECs. A total of $\sim 88 \%$ of the cells incubated for $24 \mathrm{~h}$ were positive for the dye according to flow cytometry (Fig. 4C and D).

HUVECs treated with $\mathrm{H}_{2} \mathrm{O}_{2}$ to model in vivo $\mathrm{I} / \mathrm{R}$ conditions. Cells are commonly treated with $\mathrm{H}_{2} \mathrm{O}_{2}$ to mimic I/R injury in in vitro experiments (26). In the present study, HUVEC treatment with $1 \mathrm{mM} \mathrm{H}_{2} \mathrm{O}_{2}$ for $6 \mathrm{~h}$ significantly triggered apoptosis (Fig. 5A-D), as indicated by the increase in cleaved-caspase-3 expression, whereas $10 \mathrm{mM} \mathrm{H}_{2} \mathrm{O}_{2}$ for $6 \mathrm{~h}$ preferentially caused necrosis (Fig. $5 \mathrm{E}$ and F). Therefore, $1 \mathrm{mM} \mathrm{H}_{2} \mathrm{O}_{2}$ treatment was selected for $6 \mathrm{~h}$ to mimic I/R injury.

RIPC decreases $\mathrm{H}_{2} \mathrm{O}_{2}$-induced damage in HUVECs. To examine the effects of RIPC-EPs on HUVECs treated with $\mathrm{H}_{2} \mathrm{O}_{2}$, HUVECs were incubated for $24 \mathrm{~h}$ with $4 \mu \mathrm{l}$ EPs (1x10 nanoparticles $/ \mathrm{ml})$ from the plasma of volunteers treated with sham-RIPC or RIPC, then treated with $\mathrm{H}_{2} \mathrm{O}_{2}$ $(1 \mathrm{mM} ; 6$ h). Compared with sham-RIPC EPs, RIPC-EPs 
A

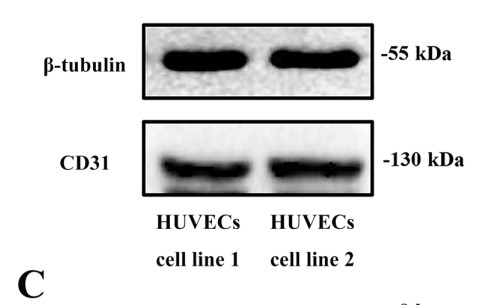

C

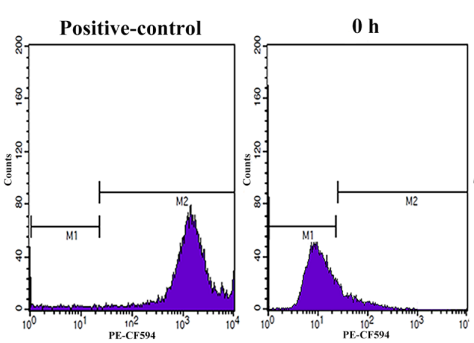

D

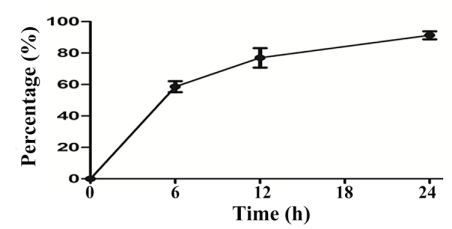

B
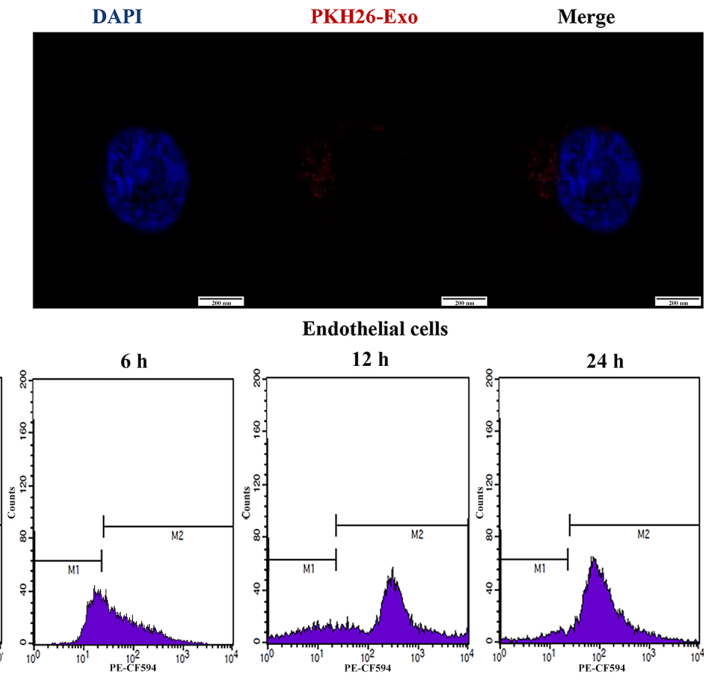

$12 \mathrm{~h}$

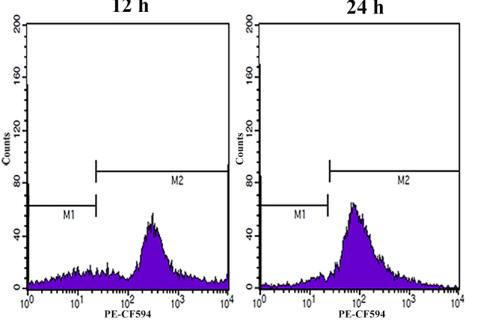

Figure 4. EP labelling and uptake by HUVECs in vitro. (A) Western blot analysis demonstrated that the cultured HUVECs had high expression of the CD31 protein (lanes 1 and 2), a marker of endothelial cells, $n=4$. (B) Representative confocal microscopy of HUVECs that were exposed to PKH26-labelled remote ischaemic preconditioning-EPs from volunteer plasma. The nuclei were stained with DAPI. Red, PKH26; blue, DAPI (nucleus); n=3. Scale bar=200 nm. (C) Flow cytometric analysis and (D) quantification of EPs taken up by HUVECs at various times, n=3. HUVECs, human umbilical vein endothelial cells; EP, extracellular particle; Exo, exosomes.

A

$\beta$-tubul
Caspas
Cleave
caspase

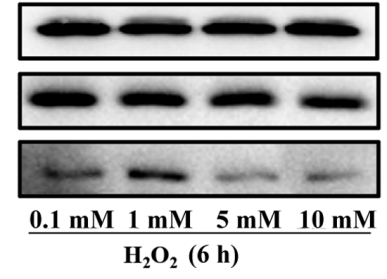

C

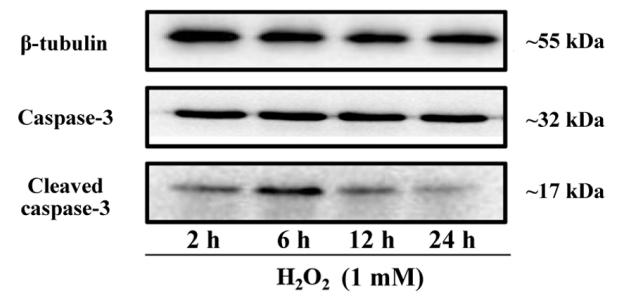

$\mathbf{E}$

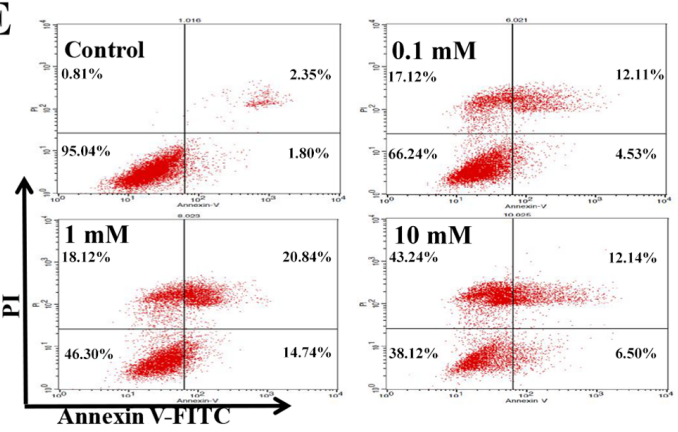

B

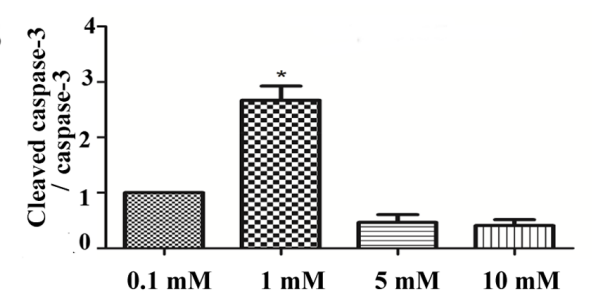

D

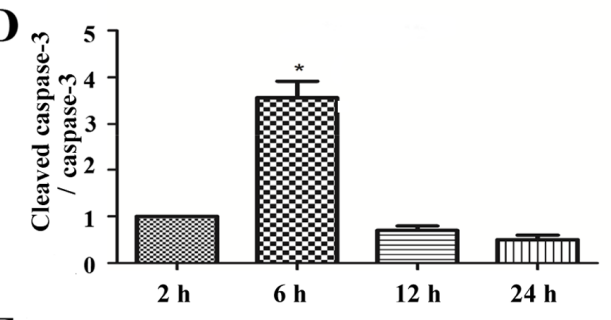

F

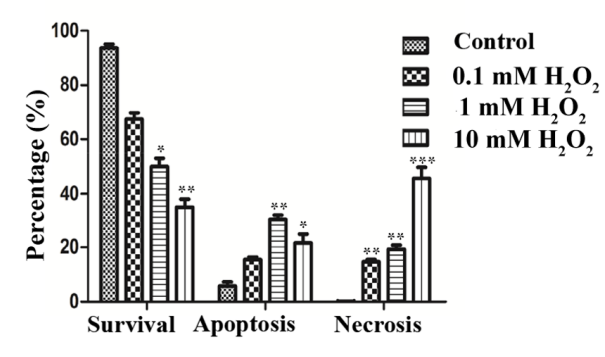

Figure 5. HUVECs treated with $\mathrm{H}_{2} \mathrm{O}_{2}$ to model in vivo conditions of ischaemia/reperfusion. (A) Caspase- 3 and cleaved caspase-3 protein levels in HUVECs treated with $\mathrm{H}_{2} \mathrm{O}_{2}$ at the indicated concentrations for $6 \mathrm{~h}$ were detected by western blotting. (B) Quantification of the western blots based on three blots. ${ }^{*} \mathrm{P}<0.05$ vs. the $0.1 \mathrm{mM}$ group, $\mathrm{n}=4$. (C) Caspase-3 and cleaved caspase-3 protein levels in HUVECs exposed to $1 \mathrm{mM}_{2} \mathrm{H}_{2}$ for the indicated times were detected by western blotting. (D) Quantification of western blots based on four blots. ${ }^{*} \mathrm{P}<0.05$ vs. the $2 \mathrm{~h}$ group, $\mathrm{n}=4$. (E and F) Apoptosis and necrosis in HUVECs treated with $\mathrm{H}_{2} \mathrm{O}_{2}$ at the indicated concentrations for $6 \mathrm{~h}$ were analysed via flow cytometry using Annexin V/PI assay. Necrosis, PI ${ }^{+}$; apoptosis, Annexin V+/PI- and Annexin V+/PI+. ${ }^{*} \mathrm{P}<0.05,{ }^{* *} \mathrm{P}<0.01$ and ${ }^{* * * *} \mathrm{P}<0.001$ vs. the Control group, $\mathrm{n}=4$. HUVECs, human umbilical vein endothelial cells; PI, propidium iodide. 
A

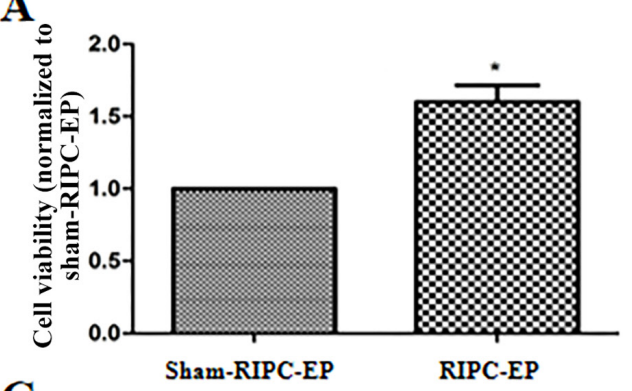

$\mathrm{C}$

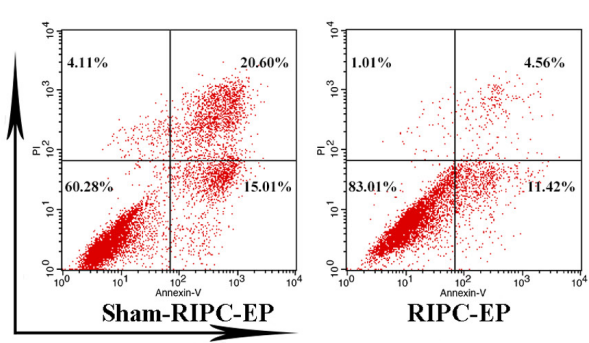

E

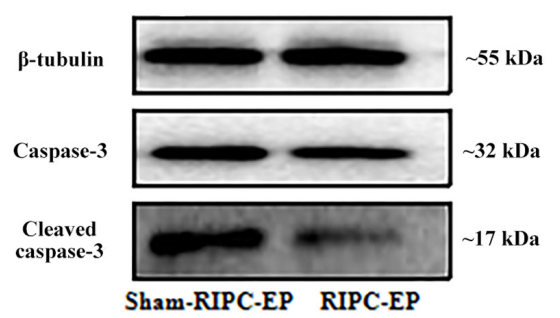

B

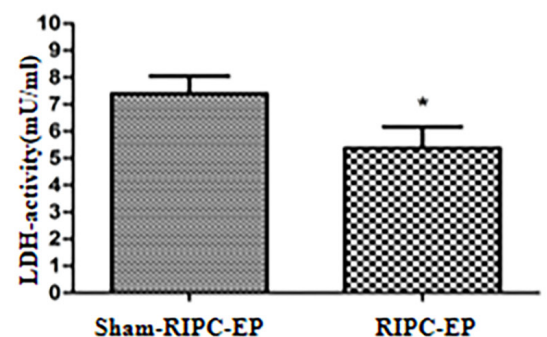

D

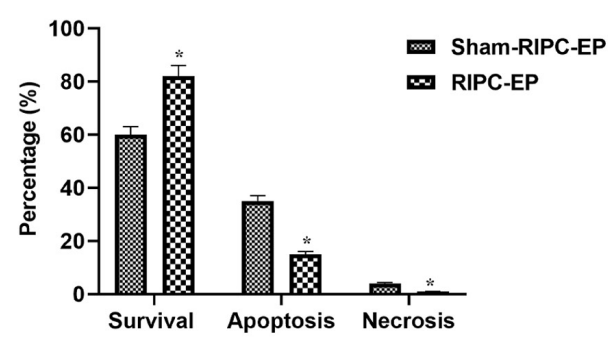

F

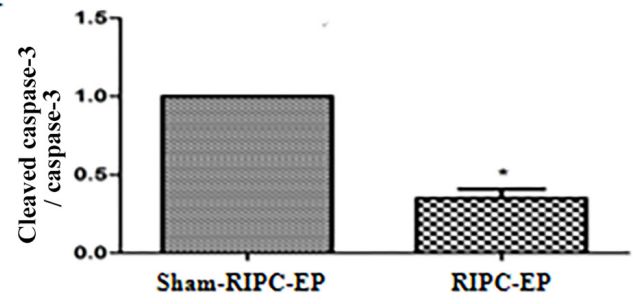

Figure 6. EPs induced by RIPC reduce $\mathrm{H}_{2} \mathrm{O}_{2}$-induced damage in HUVECs. (A) HUVECs were preincubated for $24 \mathrm{~h}$ with EPs from volunteers after RIPC, then treated with $\mathrm{H}_{2} \mathrm{O}_{2}(1 \mathrm{mM} ; 6 \mathrm{~h})$. RIPC-associated EPs were observed to enhance cell viability compared with sham-RIPC-associated EPs. $\mathrm{P}<0.05$ vs. the sham-RIPC-EP group, $n=3$. (B) Relative LDH activities in the culture media of HUVECs in the various groups. Cytotoxicity was significantly reduced by incubation for $24 \mathrm{~h}$ with RIPC-associated EPs compared with sham-RIPC-associated EPs. * $\mathrm{P}<0.05$ vs. the sham-RIPC-EP group, $\mathrm{n}=3$. (C and D) Apoptosis and necrosis in HUVECs that that preincubated for $24 \mathrm{~h}$ with EPs from human volunteers who did or did not receive $\mathrm{RIPC}$, then treated with $\mathrm{H}_{2} \mathrm{O}_{2}(1 \mathrm{mM}$; $6 \mathrm{~h})$ were analysed by flow cytometry using Annexin V/PI assay. ${ }^{*} \mathrm{P}<0.05$ vs. the sham-RIPC-EP group, $\mathrm{n}=4$. (E) HUVECs were preincubated for $24 \mathrm{~h}$ with EPs from volunteers after RIPC, then treated with $\mathrm{H}_{2} \mathrm{O}_{2}(1 \mathrm{mM} ; 6 \mathrm{~h})$. Western blot analysis of the caspase-3 and cleaved caspase-3 expression levels. Tubulin was used as an internal control. (F) Quantification of western blots based on three blots. ${ }^{*} \mathrm{P}<0.05$ vs. the sham-RIPC-EP group, $\mathrm{n}=3$. LDH, lactate dehydrogenase; RIPC, remote ischaemic preconditioning; HUVECs, human umbilical vein endothelial cells; EP, extracellular particle; PI, propidium iodide.

increased cell viability and reduced cytotoxicity in HUVECs (Fig. 6A and B). Flow cytometry results also suggested that RIPC-EPs alleviated $\mathrm{H}_{2} \mathrm{O}_{2}$-induced apoptosis and necrosis in HUVECs compared with sham-RIPC-EPs (Fig. 6C and D), accompanied by a reduced cleaved-caspase-3 to caspase-3 ratio (Fig. $6 \mathrm{E}$ and $\mathrm{F}$ ). The present results indicated a protective effect of RIPC-EPs against $\mathrm{H}_{2} \mathrm{O}_{2}$-induced cell damage in HUVECs.

Role of HIF-1 $\alpha$ in the protective effect of EPs. To elucidate whether HIF-1 $\alpha$ was involved in the protective effects of RIPC, western blot analysis was performed. RIPC significantly induced increased expression of HIF-1 $\alpha$ in the rat limb musculature (Fig. 7A and B). Compared with the sham-RIPC group, HIF-1 $\alpha$ molecular mass increased in samples from the groups treated with RIPC. The present result demonstrated that RIPC could be associated with increased levels of HIF-1 $\alpha$ and a post-translational modification may have occurred (such as hydroxylation, ubiquitination, acetylation, phosphorylation or methylation) in the HIF-1 $\alpha$ protein after RIPC treatment. When the rats received an intraperitoneal injection of $1 \mathrm{mg} / \mathrm{kg}$ Cd before RIPC, the RIPC-induced increased expression of HIF-1 $\alpha$ in the rat limbs was partially counteracted.
Cd treatment alone did not seem to have any effect on HIF-1 $\alpha$ activation (Fig. 7C and D). In addition, a significant decrease in the EP levels from the plasma of rats that received an intraperitoneal injection of Cd before RIPC was observed compared with that in the rats that received RIPC treatment alone (Fig. 7E and F). There was no statistically significant difference in the expression of HIF-1 $\alpha$ in the plasma of rats that did or did not receive RIPC (Fig. 7G).

Finally, plasma was collected from the different groups presented in Fig. 2A to assess the effects of the corresponding EPs on $\mathrm{H}_{2} \mathrm{O}_{2}$-induced cell damage in HUVECs. Compared with the control group, HUVECs treated with $1 \mathrm{mM} \mathrm{H}_{2} \mathrm{O}_{2}$ for $6 \mathrm{~h}$ had a significantly decreased cell viability, increased LDH cytotoxicity and the ratio of cleaved-caspase- 3 to caspase- 3 (Fig. 8A-D). Compared with the sham-RIPC-EP group, Cd-sham-RIPC-EP did not influence the cell viability and LDH cytotoxicity of HUVECs treated with $1 \mathrm{mM} \mathrm{H}_{2} \mathrm{O}_{2}$ for $6 \mathrm{~h}$, while RIPC-EP treatment increased cell viability and attenuated LDH cytotoxicity of HUVECs treated with $1 \mathrm{mM} \mathrm{H}_{2} \mathrm{O}_{2}$ for $6 \mathrm{~h}$, while $\mathrm{Cd}$ preconditioning partially counteracted the protective effect of RIPC-EPs (Fig. 8A and B). Compared with the sham-RIPC-EP group, Cd-sham-RIPC-EP did not influence the ratio of cleaved-caspase-3 to caspase-3 of HUVECs 
A

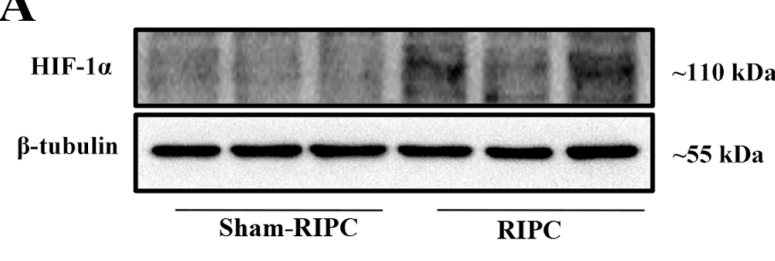

C

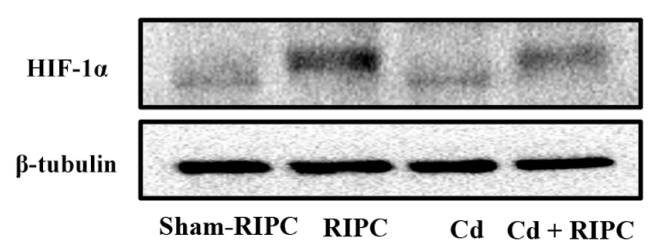

$\mathbf{E}$

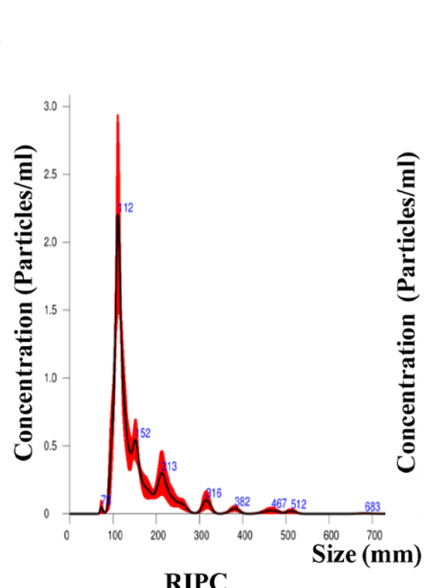

Cd Cd+RIPC $\sim 110 \mathrm{kDa}$ $\sim 55$ kDa

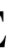

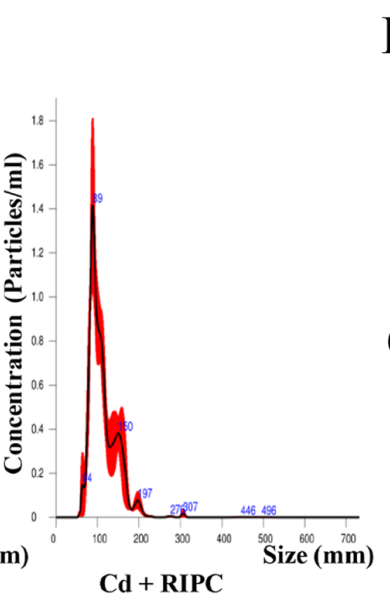

B

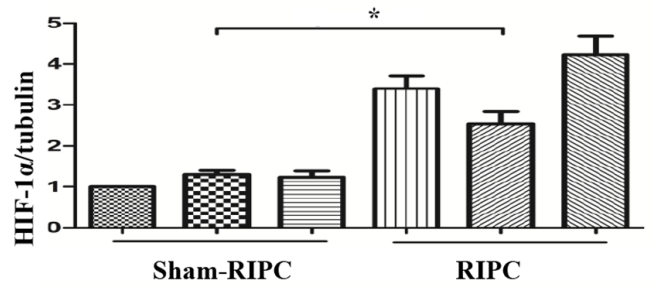

D

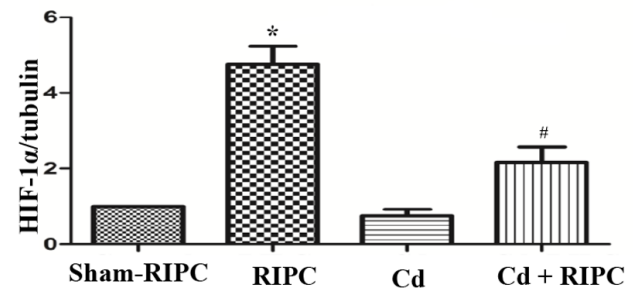

F

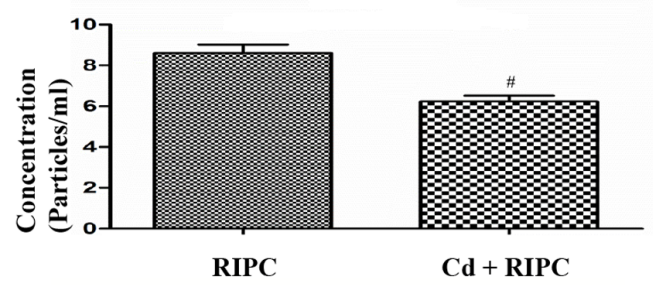

G

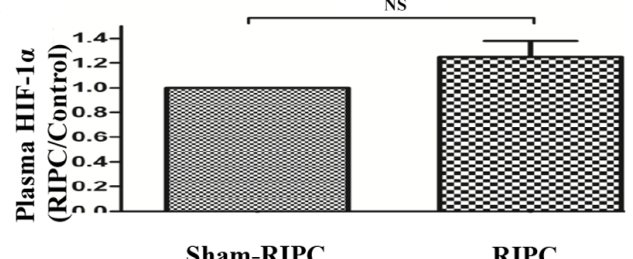

Figure 7. RIPC-induced HIF-1 $\alpha$ activation in rat limbs is inhibited by Cd. (A) Representative immunoblots of HIF-1 $\alpha$ expression in the limbs of rats that received a RIPC stimulus. The control animals were not subjected to RIPC. (B) Quantification of western blots based on three blots. "P $<0.05$ vs. the sham-RIPC group, $n=3$. (C) Representative immunoblots of HIF-1 $\alpha$ expression in the limbs of rats that did or did not receive a RIPC stimulus with or without an intraperitoneal injection of $1 \mathrm{mg} / \mathrm{kg} \mathrm{Cd} 180 \mathrm{~min}$ before RIPC. Cd pre-treatment could counteract the RIPC-induced HIF-1 $\alpha$ activation in rat limbs. The control animals did not undergo RIPC. (D) Quantification of western blots based on four blots. " $\mathrm{P}<0.05$ vs. the sham-RIPC group; "P $<0.05$ vs. the RIPC group, $\mathrm{n}=4$. (E) NTA demonstrated the size distributions of RIPC-associated and Cd-RIPC-associated exosomes, which were derived from the same volume of volunteer plasma, $\mathrm{n}=3$. (F) NTA demonstrated a significant decrease in the levels of EPs in the plasma of rats that received an intraperitoneal injection of $1 \mathrm{mg} / \mathrm{kg} \mathrm{Cd}$ 180 min before RIPC compared with those in rats that received RIPC treatment alone. ${ }^{\#} \mathrm{P}<0.05$ vs. the RIPC group, $\mathrm{n}=4$. (G) Expression of HIF-1 $\alpha$ in plasma detected by ELISA. There was no statistically significant difference in the expression of HIF-1 $\alpha$ in the plasma of rats with or without RIPC. $\mathrm{n}=4$. NTA, nanoparticle tracking analysis; RIPC, remote ischaemic preconditioning; EP, extracellular particle; HIF-1 $\alpha$, hypoxia-inducible factor 1- $\alpha$; Cd, cadmium; NS, non-significant.

treated with $1 \mathrm{mM} \mathrm{H} \mathrm{O}_{2}$ for $6 \mathrm{~h}$. RIPC-EP treatment attenuated the ratio of cleaved-caspase-3 to caspase-3 in HUVECs treated with $1 \mathrm{mM} \mathrm{H}_{2} \mathrm{O}_{2}$ for $6 \mathrm{~h}$, while $\mathrm{Cd}$ preconditioning partially counteracted the anti-apoptosis effect of RIPC-EPs (Fig. 8C and D). The present results suggested that HIF-1 $\alpha$ may contribute to the effects of RIPC.

\section{Discussion}

The main findings of the current study were as follows: i) EPs precipitated from human plasma after RIPC may contribute to reducing $\mathrm{H}_{2} \mathrm{O}_{2}$-induced damage to HUVECs in vitro; and ii) the expression of HIF-1 $\alpha$ in the rat limbs is increased during RIPC and may contribute to the protective effects of RIPC.

Recently, RIPC has emerged as an effective strategy for alleviating myocardial I/R injury $(34,35)$. The ability to use transient limb ischaemia as a RIPC stimulus has facilitated its application from bench to bedside in various clinical settings (4-6,36-40). Although the exact mechanisms of RIPC are not precisely known, the importance of neural or humoral mediators in RIPC-mediated myocardial protection of cells and organs has been emphasized in previous studies $(8-10,41,42)$; such mediators include stromal derived factor-1 $\alpha$ (43), nitrite (44), apolipoprotein A1 (45), IL-10 (46) and microRNA-144 (47), and may be present within EVs or other EPs (9-13).

In the present study, EPs from the plasma of healthy volunteers treated with sham-RIPC or RIPC were added to HUVEC cultures for $24 \mathrm{~h}$ before $\mathrm{H}_{2} \mathrm{O}_{2}$ stimulation. Since age, oestrogen levels, comorbidities and other factors may influence the protective potential of ischaemic conditioning (48-52), EPs were only collected from healthy young males. Furthermore, Abete et al (48) reported that the cytoprotective effect of plasma from RIPC-treated volunteers did not last $>60$ min after RIPC. Therefore, in the present study, EPs were collected from plasma directly after RIPC. Furthermore, $\mathrm{Cd}$ is an effective pharmacological HIF-1 $\alpha$ inhibitor $(28,29,30)$. Cd pre-treatment could counteract RIPC-induced HIF-1 $\alpha$ activation in rat 

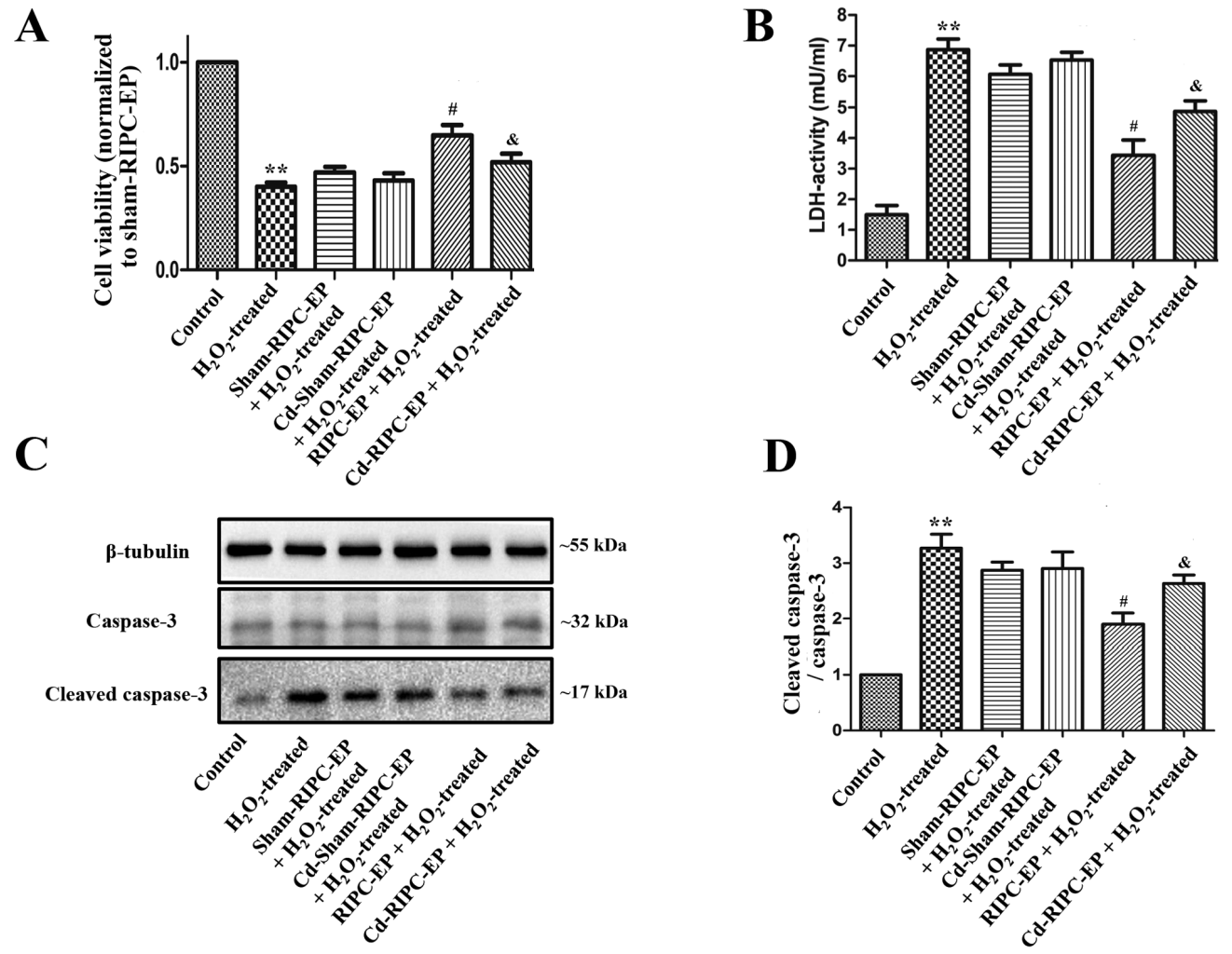

Figure 8. Cd pre-treatment partially counteracts the protective effect of EPs induced by RIPC on $\mathrm{H}_{2} \mathrm{O}_{2}$-induced cell damage in HUVECs. (A) Compared with RIPC-associated EPs, Cd-RIPC-associated EPs were observed to abolish increased cell viability. ${ }^{* *} \mathrm{P}<0.01$ vs. the control group; ${ }^{*} \mathrm{P}<0.05 \mathrm{vs}$. the sham-RIPC-EP + $\mathrm{H}_{2} \mathrm{O}_{2}$-treated group; ${ }^{\circ} \mathrm{P}<0.05$ vs. the RIPC-EP $+\mathrm{H}_{2} \mathrm{O}_{2}$-treated group, $\mathrm{n}=3$. (B) Relative $\mathrm{LDH}$ activities in the culture media of human umbilical vein endothelial cells in the various groups. Cd-RIPC-associate EPs were observed to abolish decreased cytotoxicity compared with the RIPC-associated EP group. ${ }^{* * *} \mathrm{P}<0.01$ vs. the control group; ${ }^{*} \mathrm{P}<0.05$ vs. the sham-RIPC-EP $+\mathrm{H}_{2} \mathrm{O}_{2}$-treated group; ${ }^{\circledR} \mathrm{P}<0.05$ vs. the RIPC-EP $+\mathrm{H}_{2} \mathrm{O}_{2}$-treated group, $\mathrm{n}=3$. (C) Western blot analysis of the expression levels of caspase-3 and cleaved caspase-3. Cd-RIPC-associated EPs increased the ratio of cleaved caspase-3 to caspase-3 compared with RIPC-associated EPs. Tubulin was used as an internal control. (D) Quantification of western blots based on three blots. ${ }^{* *} \mathrm{P}<0.01$ vs. the control group; ${ }^{*} \mathrm{P}<0.05$ vs. the sham-RIPC-EP $+\mathrm{H}_{2} \mathrm{O}_{2}$-treated group; ${ }^{\&} \mathrm{P}<0.05$ vs. the RIPC-EP $+\mathrm{H}_{2} \mathrm{O}_{2}$-treated group, $\mathrm{n}=3$. HUVECs, human umbilical vein endothelial cells; $\mathrm{LDH}$, lactate dehydrogenase; RIPC, remote ischaemic preconditioning; EP, extracellular particle; $\mathrm{Cd}$, cadmium.

limbs (30), resulting in loss of myocardial HIF-1 $\alpha$ activation and hypoxic preconditioning in rat hearts (28), and abolish the beneficial effects on both reduced myocardial infarction size and increased coronary flow in rats (29). Kalakech et al (30) revealed that $\mathrm{Cd}$ treatment alone $(1 \mathrm{mg} / \mathrm{kg} \mathrm{Cd}$ for $220 \mathrm{~min}$ before coronary occlusion) had no influence on infarct size in wild-type mice and HIF-1 $\alpha$ heterozygous mice. Belaidi et al $(28,29)$ also reported that $\mathrm{Cd}$ treatment alone $(1 \mathrm{mg} / \mathrm{kg})$ had no influence on HIF-1 $\alpha$ activation, haemodynamic parameters, infarct size or coronary flow in rats. Similarly, in the present experimental protocol, Cd treatment alone $(1 \mathrm{mg} / \mathrm{kg})$ had no effect on HIF-1 $\alpha$ activation. Compared with HUVECs treated with EPs from the blood of rats not receiving intraperitoneal injections of $\mathrm{Cd}, \mathrm{HUVECs}$ treated with EPs from the blood of rats receiving intraperitoneal injections of $\mathrm{Cd}$ displayed no differences in cell viability, $\mathrm{LDH}$ cytotoxicity or cleaved-caspase-3/caspase-3 ratio. Therefore, EPs from the blood of animals receiving intraperitoneal injections of $\mathrm{Cd}$ did not contain $\mathrm{Cd}$, which does not interfere with the viability of HUVECs.

A previous study has indicated that HIF-1 $\alpha$ mediated the protective effect of RIPC against myocardial I/R by activating IL-10 gene transcription (18). In another study, right atrial tissues were collected from patients subjected to RIPC or sham treatment before cardiopulmonary bypass surgery.
The results indicated that the patients subjected to RIPC exhibited reduced troponin T serum levels during the $48 \mathrm{~h}$ after surgery, and increased HIF-1 $\alpha$ levels were observed in the atrial samples (53). The present results also demonstrated that HIF-1 $\alpha$ served an important role in EP production after RIPC. Together, these results demonstrated that RIPC could be associated with increased levels of HIF-1 $\alpha$. However, the exact mechanism via which HIF-1 regulates EP biogenesis and secretion after RIPC is unclear. In previous research, HIF-1 has been reported to mediate the induction of Rab20 and Rab22 $(54,55)$, which may be involved in exosome formation and secretion $(12,56)$. In the present experiments, the molecular weight of HIF-1 $\alpha$ was observed to be slightly increased in the RIPC and Cd + RIPC groups compared with the control and $\mathrm{Cd}$ groups. We hypothesize that a post-translational modification may have occurred (such as hydroxylation, ubiquitination, acetylation, phosphorylation and methylation) in the HIF-1 $\alpha$ protein after RIPC treatment $(57,58)$.

The current investigation presents certain limitations. Firstly, the present study did not propose a detailed mechanism via which RIPC-EPs protected HUVECs against oxidative stress injury. Secondly, the present study did not establish a knockout model of the HIF-1 $\alpha$ gene in HUVECs to provide more direct evidence that HIF-1 $\alpha$ regulated EPs after RIPC. Moreover, as aforementioned, the changes in the EP levels 
that were suggested by the present data could be attributed to platelet activation during RIPC, and it is possible that these processes also influence the outcomes described in the current study.

In conclusion, the results of the current study suggested that HIF-1 $\alpha$ and plasma particular matter may contribute to the effects of RIPC on oxidative stress injury in HUVECs.

\section{Acknowledgements}

Not applicable.

\section{Funding}

The present study was funded by the National Natural Science Foundation of China (grant nos. 8156020189, 81560049, 81560051 and 82060063) and Natural Science Foundation of Jiangxi province (grant nos. 20161BAB205256 and 20202BABL216004).

\section{Availability of data and materials}

The datasets used and/or analysed during the present study are available from the corresponding author on reasonable request.

\section{Authors' contributions}

MW and FH participated in the study design, contributed to exosomes collection and cell experiments, performed the data and statistical analysis, and drafted the manuscript. ZG and $\mathrm{CH}$ participated in clinical data acquisition, contributed to data analysis and editing of the manuscript. XSC participated in the whole study design, contributed to quality control of data and images and editing and review of the manuscript. FH and XSC confirm the authenticity of all the raw data. All authors read and approved the final manuscript.

\section{Ethics approval and consent to participate}

The experiments involving human subjects were based on The Declaration of Helsinki and the European Declaration of Human Rights. The present study was approved by the Ethics Committee of the Second Affiliated Hospital of Nanchang University [Nanchang, China; approval no. SYXK(G) 2019-0007]. All animal experiments were conducted in compliance with the National Institutes of Health policies in the Guide for the Care and Use of Laboratory Animals and were approved by the Ethics Committee of the Second Affiliated Hospital of Nanchang University [Nanchang, China; approval no. SYXK(G) 2019-0102]. Written informed consents were obtained from all healthy male volunteers.

\section{Patient consent for publication}

Not applicable.

\section{Competing interests}

The authors declare that they have no competing interests.

\section{References}

1. Hausenloy DJ and Yellon DM: Remote ischaemic preconditioning: Underlying mechanisms and clinical application. Cardiovasc Res 79: 377-386, 2008.

2. Gho BC, Schoemaker RG, van den Doel MA, Duncker DJ and Verdouw PD: Myocardial protection by brief ischemia in noncardiac tissue. Circulation 94: 2193-2200, 1996.

3. Heusch G, Musiolik J, Kottenberg E, Peters J, Jakob H and Thielmann M: STAT5 activation and cardioprotection by remote ischemic preconditioning in humans: Short communication. Circ Res 110: 111-115, 2012.

4. Kttenberg E, Thielmann M, Bergmann L, Heine T, Jakob H, Heusch G and Peters J: Protection by remote ischemic preconditioning during coronary artery bypass graft surgery with isoflurane but not propofol-a clinical trial. Acta Anaesthesiol Scand 56: 30-38, 2012.

5. Ali ZA, Callaghan CJ, Lim E, Ali AA, Nouraei SA, Akthar AM, Boyle JR, Varty K, Kharbanda RK, Dutka DP and Gaunt ME: Remote ischemic preconditioning reduces myocardial and renal injury after elective abdominal aortic aneurysm repair: A randomized controlled trial. Circulation 116 (Suppl 11): I98-I105, 2007.

6. Kharbanda RK, Nielsen TT and Redington AN: Translation of remote ischaemic preconditioning into clinical practice. Lancet 374: 1557-1565, 2009.

7. Bøtker HE, Lassen TR and Jespersen NR: Clinical translation of myocardial conditioning. Am J Physiol Heart Circ Physiol 314: H1225-H1252, 2018.

8. Abel F, Murke F, Gaida M, Garnier N, Ochsenfarth C, Theiss C, Thielmann M, Kleinbongard P, Giebel B, Peters J and Frey UH: Extracellular vesicles isolated from patients undergoing remote ischemic preconditioning decrease hypoxia-evoked apoptosis of cardiomyoblasts after isoflurane but not propofol exposure. PLoS One 15: e0228948, 2020.

9. Frey UH, Klaassen M, Ochsenfarth C, Murke F, Thielmann M, Kottenberg E, Kleinbongard $\mathrm{P}$, Klenke S, Engler A, Heusch G, et al: Remote ischaemic preconditioning increases serum extracellular vesicle concentrations with altered micro-RNA signature in CABG patients. Acta Anaesthesiol Scand 63: 483-492, 2019.

10. Bartekova M, Jelemensky M and Dhalla NS: Emerging role of non-coding RNAs and extracellular vesicles in cardioprotection by remote ischemic conditioning of the heart. Rev Cardiovasc Med 20: 59-71, 2019.

11. Ratajczak J, Wysoczynski M, Hayek F, Janowska-Wieczorek A and Ratajczak MZ: Membrane-derived microvesicles: Important and underappreciated mediators of cell-to-cell communication. Leukemia 20: 1487-1495, 2006.

12. Colombo M, Raposo G and Théry C: Biogenesis, secretion, and intercellular interactions of exosomes and other extracellular vesicles. Annu Rev Cell Dev Biol 30: 255-289, 2014.

13. Raposo G and Stoorvogel W: Extracellular vesicles: Exosomes, microvesicles, and friends. J Cell Biol 200: 373-383, 2013.

14. Semenza GL: A compendium of proteins that interact with HIF-1 $\alpha$. Exp Cell Res 356: 128-135, 2017.

15. Aga M, Kondo S, Wakisaka N, Moriyama-Kita M, Endo K, Nakanishi Y, Murono S, Sugimoto H, Ueno T and Yoshizaki T: Siah-1 is associated with expression of hypoxia-inducible factor- $1 \alpha$ in oral squamous cell carcinoma. Auris Nasus Larynx 44: 213-219, 2017.

16. Kosaka N, Iguchi H, Hagiwara K, Yoshioka Y, Takeshita F and Ochiya T: Neutral sphingomyelinase 2 (nSMase2)-dependent exosomal transfer of angiogenic microRNAs regulate cancer cell metastasis. J Biol Chem 288: 10849-10859, 2013.

17. Hubbi ME and Semenza GL: Regulation of cell proliferation by hypoxia-inducible factors. Am J Physiol Cell Physiol 309: C775-C782, 2015.

18. Cai Z, Luo W, Zhan H and Semenza GL: Hypoxia-inducible factor 1 is required for remote ischemic preconditioning of the heart. Proc Natl Acad Sci USA 110: 17462-17467, 2013.

19. Seal JB and Gewertz BL: Vascular dysfunction in ischemia/reperfusion injury. Ann Vasc Surg 19: 572-584, 2005.

20. Michiels C: Endothelial cell functions. J Cell Physiol 196: 430-443, 2003.

21. Pitcher JM, Wang M, Tsai BM, Kher A, Turrentine MW, Brown JW and Meldrum DR: Preconditioning: Gender effects. J Surg Res 129: 202-220, 2005. 
22. Kharbanda RK, Peters M, Walton B, Kattenhorn M, Mullen M, Klein N, Vallance P, Deanfield J and MacAllister R: Ischemic preconditioning prevents endothelial injury and systemic neutrophil activation during ischemia-reperfusion in humans in vivo. Circulation 103: 1624-1630, 2001.

23. Randhawa PK and Jaggi AS: Exploring the putative role of TRPV $_{1}$-dependent CGRP release in remote hind preconditioning-induced cardioprotection. Cardiovasc Ther 35, 2017.

24. Yamaguchi T, Izumi Y, Nakamura Y, Yamazaki T, Shiota M, Sano S, Tanaka M, Osada-Oka M, Shimada K, Miura K, et al: Repeated remote ischemic conditioning attenuates left ventricular remodeling via exosome-mediated intercellular communication on chronic heart failure after myocardial infarction. Int J Cardiol 178: 239-246, 2015.

25. Sera T, Kohno T, Nakashima $Y$, Uesugi $M$ and Kudo $S$ : Low-frequency oscillations of finger skin blood flow during the initial stage of cold-induced vasodilation at different air temperatures. J Physiol Anthropol 39: 37, 2020.

26. Yang Y, Li Y, Chen X, Cheng X, Liao Y and Yu X: Exosomal transfer of miR-30a between cardiomyocytes regulates autophagy after hypoxia. J Mol Med (Berl) 94: 711-724, 2016.

27. Jiang F, Xu XR, Li WM, Xia K, Wang LF and Yang XC: Monotropein alleviates $\mathrm{H} 2 \mathrm{O} 2$-induced inflammation, oxidative stress and apoptosis via NF- $\mathrm{\kappa B} / \mathrm{AP}-1$ signaling. Mol Med Rep 22: 4828-4836, 2020.

28. Belaidi E, Beguin PC, Levy P, Ribuot C and Godin-Ribuot D Prevention of HIF-1 activation and iNOS gene targeting by low-dose cadmium results in loss of myocardial hypoxic preconditioning in the rat. Am J Physiol Heart Circ Physiol 294: H901-H908, 2008.

29. Belaidi E, Beguin PC, Levy P, Ribuot C and Godin-Ribuot D: Delayed myocardial preconditioning induced by cobalt chloride in the rat: HIF-1 $\alpha$ and iNOS involvement. Fundam Clin Pharmacol 26: 454-462, 2012.

30. Kalakech H, Tamareille S, Pons S, Godin-Ribuot D, Carmeliet P, Furber A, Martin V, Berdeaux A, Ghaleh B and Prunier F: Role of hypoxia inducible factor- $1 \alpha$ in remote limb ischemic preconditioning. J Mol Cell Cardiol 65: 98-104, 2013.

31. Chun YS, Choi E, Kim GT, Choi H, Kim CH, Lee MJ, Kim MS and Park JW: Cadmium blocks hypoxia-inducible factor (HIF)-1-mediated response to hypoxia by stimulating the proteasome-dependent degradation of HIF-1alpha. Eur J Biochem 267: 4198-4204, 2000.

32. Jungmann J, Reins HA, Schobert C and Jentsch S: Resistance to cadmium mediated by ubiquitin-dependent proteolysis. Nature 361: 369-371, 1993.

33. Liu L and Shi GP: CD31: Beyond a marker for endothelial cells Cardiovasc Res 94: 3-5, 2012.

34. Sanada S, Komuro I and Kitakaze M: Pathophysiology of myocardial reperfusion injury: Preconditioning, postconditioning, and translational aspects of protective measures. Am J Physiol Heart Circ Physiol 301: H1723-H1741, 2011.

35. Wang X, Zhu H, Zhang X, Liu Y, Chen J, Medvedovic M, Li H, Weiss MJ, Ren X and Fan GC: Loss of the miR-144/451 cluster impairs ischaemic preconditioning-mediated cardioprotection by targeting Rac-1. Cardiovasc Res 94: 379-390, 2012.

36. Wagner R, Piler P, Bedanova H, Adamek P, Grodecka L and Freiberger T: Myocardial injury is decreased by late remote ischaemic preconditioning and aggravated by tramadol in patients undergoing cardiac surgery: A randomised controlled trial. Interact Cardiovasc Thorac Surg 11: 758-762, 2010.

37. Cheung MM, Kharbanda RK, Konstantinov IE, Shimizu M, Frndova H, Li J, Holtby HM, Cox PN, Smallhorn JF, Van Arsdell GS and Redington AN: Randomized controlled trial of the effects of remote ischemic preconditioning on children undergoing cardiac surgery: First clinical application in humans. J Am Coll Cardiol 47: 2277-2282, 2006.

38. Hausenloy DJ and Yellon DM: The therapeutic potential of ischemic conditioning: An update. Nat Rev Cardiol 8: 619-629, 2011.

39. Thielmann M, Wendt D, Tsagakis K, Price V, Dohle DS, Pasa $\mathrm{S}$ and Kottenberg E: Remote ischemic preconditioning: The surgeon's perspective. J Cardiovasc Med (Hagerstown) 14: $187-192,2013$

40. Veighey K and Macallister RJ: Clinical applications of remote ischemic preconditioning. Cardiol Res Pract 2012: 620681, 2012

41. Pickard JM, Davidson SM, Hausenloy DJ and Yellon DM: Co-dependence of the neural and humoral pathways in the mechanism of remote ischemic conditioning. Basic Res Cardiol 111: $50,2016$.
42. Oba T, YasukawaH,Nagata T, Kyogoku S, Minami T, Nishihara M, Ohshima H, Mawatari K, Nohara S, Takahashi J, et al: Renal nerve-mediated erythropoietin release confers cardioprotection during remote ischemic preconditioning. Circ J 79: 1557-1567, 2015.

43. Bromage DI, Davidson SM and Yellon DM: Stromal derived factor 1 $\alpha$ : a chemokine that delivers a two-pronged defence of the myocardium. Pharmacol Ther 143: 305-315, 2014.

44. Rassaf T, Totzeck M, Hendgen-Cotta UB, Shiva S, Heusch G and Kelm M: Circulating nitrite contributes to cardioprotection by remote ischemic preconditioning. Circ Res 114: 1601-1610, 2014.

45. Hibert P, Prunier-Mirebeau D, Beseme O, Chwastyniak M Tamareille S, Lamon D, Furber A, Pinet F and Prunier F: Apolipoprotein A-I is a potential mediator of remote ischemic preconditioning. PLoS One 8: e77211, 2013.

46. Cai ZP, Parajuli N, Zheng X and Becker L: Remote ischemic preconditioning confers late protection against myocardial ischemia-reperfusion injury in mice by upregulating interleukin-10. Basic Res Cardiol 107: 277, 2012.

47. Li J, Rohailla S, Gelber N, Rutka J, Sabah N, Gladstone RA, Wei C, Hu P, Kharbanda RK and Redington AN: MicroRNA-144 is a circulating effector of remote ischemic preconditioning. Basic Res Cardiol 109: 423, 2014.

48. Abete P, Ferrara N, Cacciatore F, Madrid A, Bianco S, Calabrese C, Napoli C, Scognamiglio P, Bollella O, Cioppa A, et al: Angina-induced protection against myocardial infarction in adult and elderly patients: A loss of preconditioning mechanism in the aging heart? J Am Coll Cardiol 30: 947-954, 1997.

49. Ebrahim Z, Yellon DM and Baxter GF: Ischemic preconditioning is lost in aging hypertensive rat heart: Independent effects of aging and longstanding hypertension. Exp Gerontol 42: 807-814, 2007.

50. Ferdinandy P, Schulz R and Baxter GF: Interaction of cardiovascular risk factors with myocardial ischemia/reperfusion injury, preconditioning, and postconditioning. Pharmacol Rev 59: 418-458, 2007

51. Babiker F, Al-Jarallah A and Al-Awadi M: Effects of cardiac hypertrophy, diabetes, aging, and pregnancy on the cardioprotective effects of postconditioning in male and female rats. Cardiol Res Pract 2019: 3403959, 2019.

52. Weber NC, Riedemann I, Smit KF, Zitta K, van de Vondervoort D, Zuurbier CJ, Hollmann MW, Preckel B and Albrecht M: Plasma from human volunteers subjected to remote ischemic preconditioning protects human endothelial cells from hypoxia-induced cell damage. Basic Res Cardiol 110: 17, 2015.

53. Albrecht M, Zitta K, Bein B, Wennemuth G, Broch O, Renner J, Schuett T, Lauer F, Maahs D, Hummitzsch L, et al: Remote ischemic preconditioning regulates HIF- $1 \alpha$ levels, apoptosis and inflammation in heart tissue of cardiosurgical patients: A pilot experimental study. Basic Res Cardiol 108: 314, 2013.

54. Hackenbeck T, Huber R, Schietke R, Knaup KX, Monti J, Wu X, Klanke B, Frey B, Gaipl U, Wullich B, et al: The GTPase RAB20 is a HIF target with mitochondrial localization mediating apoptosis in hypoxia. Biochim Biophys Acta 1813: 1-13, 2011.

55. Wang T, Gilkes DM, Takano N, Xiang L, Luo W, Bishop CJ, Chaturvedi P, Green JJ and Semenza GL: Hypoxia-inducible factors and RAB22A mediate formation of microvesicles that stimulate breast cancer invasion and metastasis. Proc Natl Acad Sci USA 111: E3234-E3242, 2014

56. Ostrowski M, Carmo NB, Krumeich S, Fanget I, Raposo G, Savina A, Moita CF, Schauer K, Hume AN, Freitas RP, et al: Rab27a and Rab27b control different steps of the exosome secretion pathway. Nat Cell Biol 12: 19-30, 2010.

57. Ke Q and Costa M: Hypoxia-inducible factor-1 (HIF-1). Mol Pharmacol 70: 1469-1480, 2006.

58. Bao L, Chen Y, Lai HT, Wu SY, Wang JE, Hatanpaa KJ, Raisanen JM, Fontenot M, Lega B, Chiang CM, et al: Methylation of hypoxia-inducible factor (HIF)-1 $\alpha$ by G9a/GLP inhibits HIF-1 transcriptional activity and cell migration. Nucleic Acids Res 46: 6576-6591, 2018

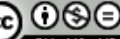

This work is licensed under a Creative Commons Attribution-NonCommercial-NoDerivatives 4.0 International (CC BY-NC-ND 4.0) License. 